\section{Occupational Health Service: Beginning or End?}

The Employment Medical Advisory Service (E.M.A.S.) Bill ${ }^{1}$ introduced in the Commons recently by the Government has now had its second reading. If it is passed the appointed factory doctor will go and H.M. medical inspector of factories will become an employment medical adviser (E.M.A.) separate from the Factory Inspectorate but still under the aegis of the Department of Employment. The E.M.A. will retain the duties of medically policing the factories, with powers which will cover entry to premises, the disclosure of information, and the compulsory attendance of an employee for medical examination. The medical adviser will also be able to compel an employer to pay for any further radiological or laboratory investigation of the employee that the E.M.A. may require. The new legislation will make him responsible for advising on the employment of all disabled young persons, and for keeping the Minister informed on matters concerning the safeguard and the improvement of the health of persons training for employment.

The main change from Mrs. Barbara Castle's previous Bill $^{2}$ is the abolition of the contentious compulsory school leaving medical certificate. This would have branded a disabled pupil for the first three years of his working life, and enabled an unscrupulous employer to reject all but the fit. The B.M.A. strongly objected to the idea of such a damning certificate. Nevertheless, though it will not be compulsory for the E.M.A. to see all the disabled school leavers, the Bill makes provision for the local careers office to inform him not only of a disabled pupil about to leave school to seek employment, but also of any disabled young persons who have just been accepted for employment in, or transferred within, a factory. This is obviously a far better system than the sketchy and medically isolated examination of young persons that the appointed factory doctor is at present carrying out.

Another innovation will be that local education authorities must arrange for one of their medically qualified staff to supply the E.M.A. with the school medical record cards. If only the proposals had gone to their logical conclusionand the Employment Medical Advisory Service had been placed within the Health Service-then the E.M.A. could have approached the disabled young person's general practitioner directly for the complete medical record. This is one of the reasons why the B.M.A. in its discussions with the Government on the reorganization of the N.H.S. has urged the setting up of a comprehensive national occupational health service as part of the N.H.S. The Association has been concerned about the structure of the proposed E.M.A.S. because it could indefinitely delay such a development. Introducing the second reading of the Bill the Government spokesman, Mr. Dudley Smith, said that the new service was not intended to be a comprehensive industrial health service. ${ }^{3} \mathrm{He}$ also made it clear that "the responsibility for occupational medicine and in particular for the E.M.A.S. must for the present-I emphasize the present-remain with the Department of Employment," though he promised that when the N.H.S. was reorganized "the proper home of the Employment Medical Advisory Service will undoubtedly have to be looked at again by the Departments concerned." So there appears to be hope that eventually the N.H.S. may include a comprehensive national occupational health and hygiene service. Such a service is envisaged for all the signatories of the Treaty of Rome and it would be as extensive as those that now exist in several European countries such as France and Holland.

One aspect of the new Bill not mentioned in the Minister's speech concerned the power proposed for the Chief Employment Medical Adviser (C.E.M.A.) if he wishes to carry out a survey. He will be able to arrange as many blood, urine, and $x$-ray tests on as many men in as many firms as he requires if, in his opinion, their "health has been, or is being injured, or it is possible that it has been, is being or will be injured by reason of the nature of their work." These objectives are admirable, but the employer cannot appeal against paying the cost of such a survey nor against the C.E.M.A.'s power to decide when and where these tests shall be carried out. On this latter point, Mr. Dudley Smith said: "It is proposed that National Health Service laboratories should be used for most E.M.A.S. work." 2 The only restraint would be the extent to which the already overstretched N.H.S. could take on the extra work. If in some areas hospital laboratories and $x$-ray departments were unable to help then the C.E.M.A. would have to fall back on his own department's laboratories, and those universityaffiliated occupational hygiene laboratories which have been carefully built up with doctors, chemists, and physicists working full time in the occupational medicine field. It would be more sensible if these specialized university occupational hygiene laboratories-sited in London, Manchester, Cardiff, Newcastle upon Tyne, and Dundee-were to be used by the E.M.A.S. in the first instance, with N.H.S. hospitals help being called upon only if these laboratories could not cope.

In fact, if the C.E.M.A. is allowed to by-pass these laboratories, which are now bearing the brunt of this specialized work and are geographically well placed, then a well-tried service could go to the wall, not for lack of resources but because of deliberate Government policy. If this happened then the teaching of occupational health and hygiene would be hampered at a time when approaching entry into the Common Market should be prompting the training of more occupational health physicians and hygienists to man the national occupational health service that Britain needs.

\footnotetext{
Employment Medical Advisory Service Bill. London, H.M.S.O., 1971.

Employed Persons (Health and Safety) Bill. London, H.M.S.O., 1970.

3 Hansard, 1971, 828, No. 30, 121-180.
}

\section{Hypothalamic Releasing Hormones}

The hypothalamus controls anterior pituitary function by regulatory substances secreted into the portal venous system flowing from the hypothalamus to the anterior lobe. Releasing factors, or releasing hormones, as the substances are termed, which affect the release of each of the seven anterior pituitary hormones have been identified. Release of thyrotrophin (TSH), adrenocorticotrophin (ACTH), growth hormone (GH), follicle-stimulating hormone (FSH), and 